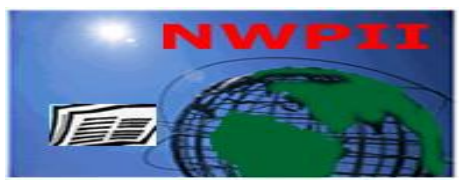

American Journal of

Biomedical Sciences

ISSN: 1937-9080

nwpii.com/ajbms

\title{
Study the Oral Toxicity of Zinc Oxide Nanoparticles in Adult Mice
}

\author{
Rasha S. Shams Eldine
}

Medical Biophysics Department,Medical Research Institute, Alexandria University,Egypt

*Corresponding Author

Rasha S. Shams Eldine

Medical Biophysics Department,Medical Research Institute

Alexandria University

Egypt

Email:rasha_shams17@yahoo.com

Received:14 October 2020; | Revised:25 October 2020; | Accepted:06 March 2021

\begin{abstract}
ZnO-NPs suspended in distilled water were administered to mice at dose of $100 \mathrm{mg} / \mathrm{kg}$ body weight through oral gavage. The mean body weight gain in mice given ZnO-NPs was similar to this of control group during the two weeks. The effects of ZnONPs on RBCs have been investigated in context with the osmotic fragility, all of the RBCs did not hemolyze at the same time when treated with ZnONPs, some RBCs took more time, and some became crenated while some remained turgid for relatively longer duration. ZnONPs can spread more in blood, kidney, liver and other organs, and this was supported by the histopathological section showed that ZnONPs is able to induce changes in tissues of kidney and liver and brain in mice. The toxic effects of zinc oxide nanoparticles on the central nervous system include cytotoxicity, inflammation, and oxidative stress induction that result in neurodegeneration.
\end{abstract}

Keywords: ZnO-NPs, Osmotic fragility, Oxidative stress

\section{Introduction}

Recently, rapid advances in nanotechnology have contributed to manufacture and control of engineered nanoparticles, which are generally defined as particles in the size range of 1-100 nm in one dimension ${ }^{[1]}$.

Nanoparticles have special physical and chemical properties and unusual shape, size and surface area to volume ratio. Mentioned features make these materials unique for biological, medical and industrial applications. One of the most useful features is high surface area that causes nanoparticle's widespread application in medical sciences and production of Nano based drugs for some of the Incurable disease ${ }^{[1]}$. On the other hand, this material distributed in all of body rapidly after injection by circulation and reached to the all of the organs and tissues ${ }^{[2]}$. So pollution of our living environment by nanoparticles is very dangerous because they can interact with macromolecules in living cells, while we don't have enough information and suitable model for the action of these materials in the body. ${ }^{[3]}$

Zinc oxide $(\mathrm{ZnO})$ is one of the most commonly utilized materials in diverse industrial fields such as dyes, paints, pigments, metallurgy additives, rubber, alloys, ceramics, chemical fibers, electronics, 
catalyst, medical diagnosis, sunscreens, cosmetics, personal care products, and food additives ${ }^{[4-5]}$. The wide range of applications of $\mathrm{ZnO}$ is attributed to their unique characteristics, including semiconducting, electrical, optical, catalytic, magnetic, antimicrobial and ultraviolet light absorption properties. ${ }^{[6-7]}$

Zinc oxide nanoparticles (ZnONps) are semiconductor metal oxide nanoparticles that are widely used in biomedical fields as an anticancer drug, a tool for imaging biological systems, and also in cosmetics. ${ }^{\text {[7] }}$

Therefore the aim of this work is to evaluate the oral toxicity of zinc oxide nanoparticles on the red blood cells (fragility test) and the changes of the liver, kidney\& brain of mice.

\section{Materials and Methods}

\subsection{Preparation of Zinc oxide nanoparticles}

Zinc sulfate heptahydrate and sodium hydroxide were used in the experiment, and deionized water is used for the preparation of solutions. To the aqueous solution of zinc sulfate, sodium hydroxide solution was added slowly drop wise in a molar ratio of 1:2 under vigorous stirring, and the stirring was continued for $12 \mathrm{~h}$. The precipitate obtained was filtered and washed thoroughly with deionized water. The precipitate was dried in an oven at $100^{\circ} \mathrm{C}$ and ground to fine powder using agate mortar. The powder obtained from the above method was calcined at $72^{\circ} \mathrm{C}$ for 24 hours.

\subsection{Characterization}

\subsubsection{X-ray diffraction (XRD) of ZnONPs}

The crystallinity was determined by XRD powder diffraction. Analysis was performed by using an XRD SHIMADZU 6000 diffractometer equipped with a $\mathrm{Cuk} \alpha\left(\mathrm{K}=1.54 \mathrm{~A}^{\circ}\right)$ source, maintaining applied voltage of $40 \mathrm{kV}$ and current at $30 \mathrm{~mA}$. About $0.3 \mathrm{~g}$ of dried $\mathrm{ZnO}-\mathrm{NPs}$ was deposited as a randomly oriented powder into a plexiglass sample container and the XRD patterns were recorded between $5^{\circ}$ and $50^{\circ}$ angles, with a speed of $5.0^{\circ} / \mathrm{min}$.
The crystalline domain Diameter (D) was obtained from XRD peaks using the following Scherrer's equation $\mathrm{D}=\mathrm{K} * \lambda / \beta * \cos \theta$, where $\lambda$ is the wavelength of the incident $X$-ray beam; $\Theta$ the Bragg's diffraction angle; $\beta$ the width of the X-ray pattern line at half peak-height in radian and the dimensionless shape factor $(\mathrm{K})$ has a typical value of 0.89 , but varies with the actual shape of the crystalline ${ }^{[8]}$.

\subsubsection{Transmission electron microscopy (TEM) of $\mathrm{ZnO}$-NPs}

The size distribution of ZnO-NPs in suspension was measured using a submicrometer particle size analyzer (Nicomp,Port Richey, FL) and was confirmed to be within the designated range. Images of NP in the vehicle were also obtained by TEM (JEM-2010, JEOL, Tokyo, Japan).

\subsection{Experimental animals}

Twenty albino male mice obtained from the animal house. The age of mice was 3 weeks, and the weight was 20-25 gm. Animals cages were kept in standardized conditions $\left(25 \pm 5{ }^{\circ} \mathrm{C}, 12 \mathrm{hrs}\right.$. light/ dark cycle). In this study, the male albino mice were divided into two groups (each group comprises 10 mice).

The First group (control group) received general food and water.

The second group was oral gavages by $(100$ $\mathrm{mg} / \mathrm{ml}$ ) body weight of $\mathrm{ZnO} \mathrm{Nps}$.

All animals were sacrificed after two weeks at the end of experiment.

A small piece of liver and kidney and brain were taken and fixed in $10 \%$ formalin solution, after that routine histological preparation was conducted $^{[9]}$.

Use of experimental animals in the study protocol will be carried out with the ethical guidelines of the Medical Research Institute, Alexandria University (Appendix 2, Guiding Principles for Biomedical Research Involving Animals, 2011).

For the two previous groups the followings were done.

\subsection{Osmotic fragility Study of the RBC' $\mathrm{s}$}

Whole blood samples were collected in EDTA from the heart, preferably the ventricle, which can 
be accessed either via the left side of the chest, through the diaphragm, from the top of the sternum. Voiles and treated with RBC diluting fluid to lyse the WBCs. In order to lyse the RBCs the resultant mixture was treated with varied concentrations between 0.1 to $1.2 \% \mathrm{NaCl}^{[10]}$.

The supernatant absorption was measured using spectrophotometer at $540 \mathrm{~nm}$ using UVSpectrophotometer (Shimadzu, UV-1800, UVSpectrophotometer, Japan)

The morphological changes of the RBC's were examined using Bright field microscopy.

V Histopathological studies

Specimens from each of the followings organs ( liver, kidney \& brain ) were subjected to the general routine technique for tissue preparation.

\section{Results}

\subsection{X-ray Diffraction of ZnONPs}

Figure (1) represents the XRD pattern of ZnONPs . A definite line broadening of XRD peaks indicates that the prepared material consists of particles in the Nano scale range. From this XRD patterns analysis, we determined peak intensity, position and width. Diffraction lines of $\mathrm{ZnO}$ were broadened and diffraction broadening was found dependent on Miller indices of the corresponding sets of crystal planes. For most samples the diffraction line 4000 is narrower than the line 8000 and 8000 narrower than the line 5000. The average crystallite size of samples S2 $\left(700^{\circ} \mathrm{C}\right)$ and S3 $\left(900^{\circ} \mathrm{C}\right)$ were determined by the Debye-Scherer formula $0.9 \lambda / \mathrm{B} \cos (\theta)$ and were found to be $26.74 \mathrm{~nm}$ and $28.93 \mathrm{~nm}$, respectively. Comparing the XRD report of three samples it has been concluded that the samples calcined at $700^{\circ} \mathrm{C}$ and $900^{\circ} \mathrm{C}$ gives a high intensity fine peaks.

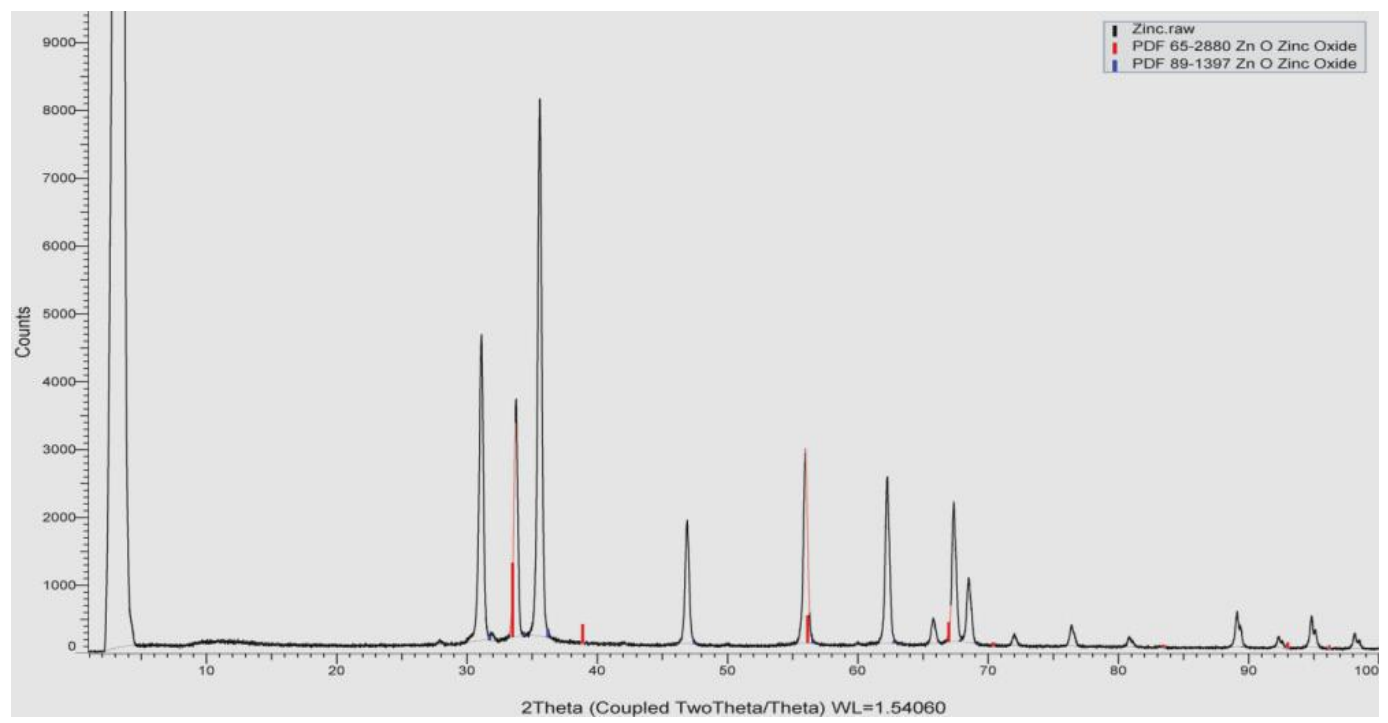

Figure 1: XRD pattern of $\mathrm{ZnONPs}$ synthesized at calcining temperatures $500^{\circ} \mathrm{C}$

\subsection{Transmission electron microscopy (TEM) of ZnO-NPs}

Figure (2) shows the TEM images and selected area electron diffraction patterns of $\mathrm{ZnO}-\mathrm{NPs}$ annealed at $700^{\circ} \mathrm{C}$ and $900^{\circ} \mathrm{C}$. This image reveals that the product consists of spherical particles with the average size of $<100 \mathrm{~nm}$. The selected Area Electron Diffraction (SAED) shows the crystalline structure, complexity for variable calcination. It indicates that $\mathrm{ZnO}$-NPs are not single crystals, rather are the aggregation of several single crystals. 


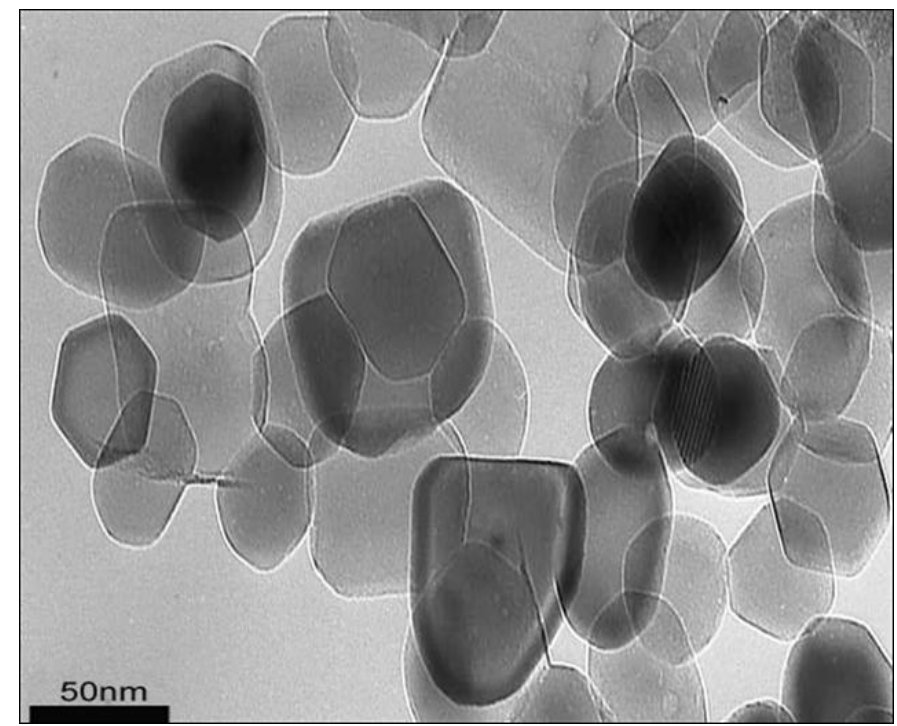

Figure 2: Transmission electron microscopy (TEM) images of synthesized ZnO nanoparticles

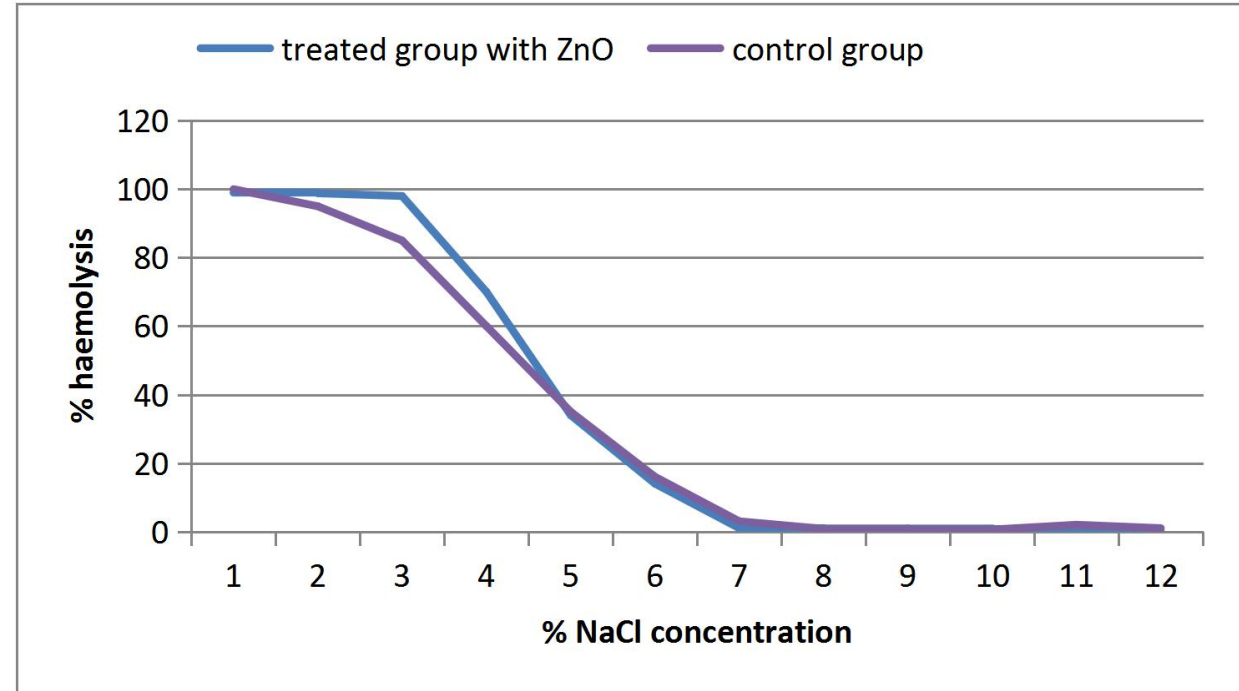

The Figure (3): Osmotic fragility curve for RBCs for both control \& treated group

The RBCs of the $\mathrm{ZnO}$ treated group begins to lyse approximately at the same time to the normal cell

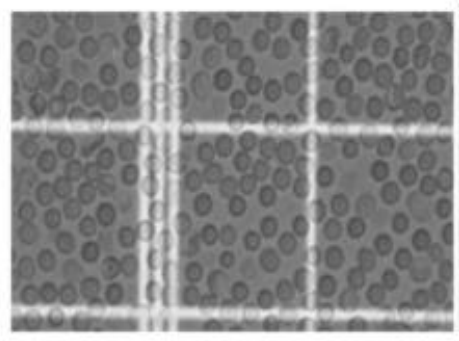

A

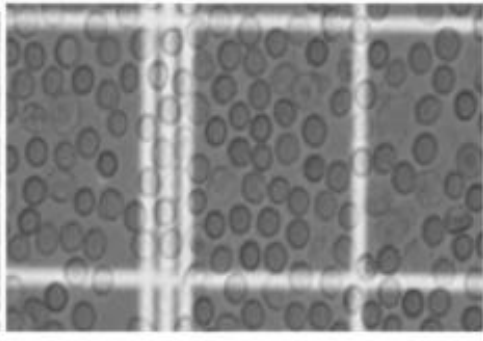

B

Figure 4: The morphological changes of RBC's under Bright field microscopy for both control group $A$, treated group with $\mathrm{ZnO}$ nanoparticles $B$

A:normal round shapes of RBCs. B:RBCs. of the treated group with nanoparticles showing swollen, crenation and lysed cells. 

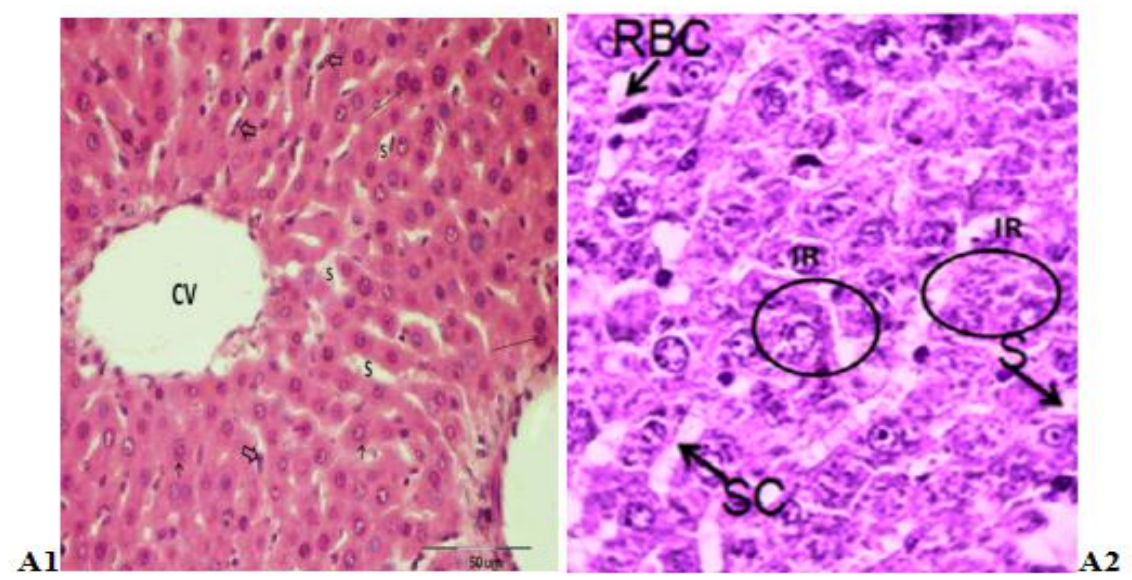

Figure 5: Histopathology of liver tissues in rats treated with $\mathrm{ZnO}-\mathrm{NPs}(100 \mathrm{mg} / \mathrm{Kg})$ for 5 consecutive day (A1)Control group showing normal hepatocytes with central vein (CV). A2 pathological alterations in the liver of ZnO-NPs (100 mg/kg) treated rats manifested by sinusoidal congestion (SC) and RBC (Red Blood Cells) deposit and inflammatory response (IR),Sinusoide (S) mononucleated $(\uparrow)$ and binucleated hepatocytes (thin arrow) A1 and A2magnification $\mathrm{x} 400$

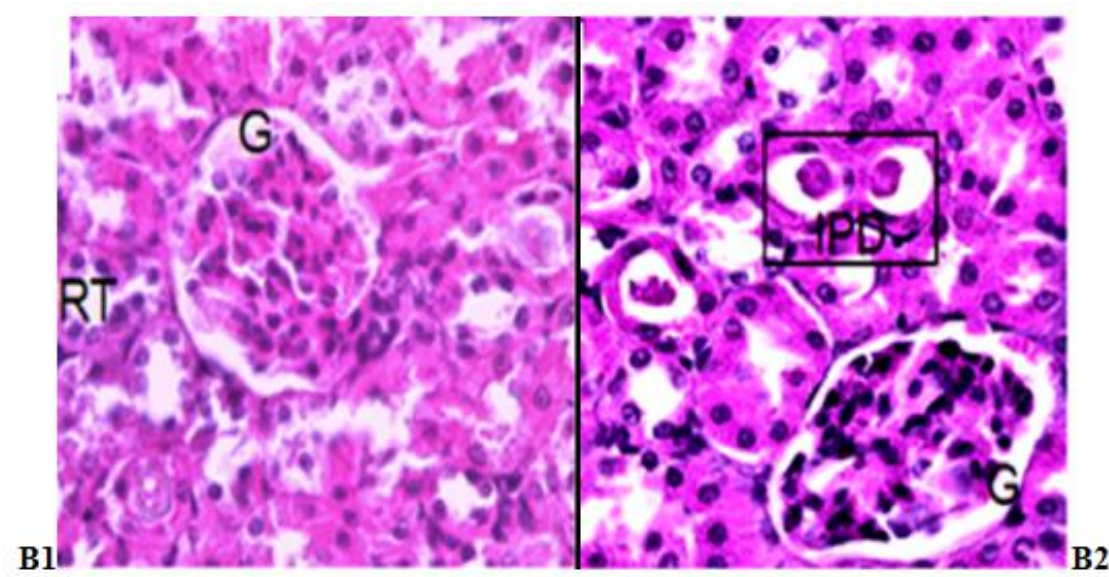

Figure 6: Histopathology of kidney tissues in rats treated with $\mathrm{ZnO}-\mathrm{NPs}(100 \mathrm{mg} / \mathrm{Kg})$ for 5 consecutive days B1 control group showing normal architecture of renal corpuscles with their glomeruli $(G)$ and renal tubules (RT); B2 treated group showing intratubular protein deposition (IPD) but no significant glomerular changes (G). B1 and B2 magnification $\mathrm{x} 400$.

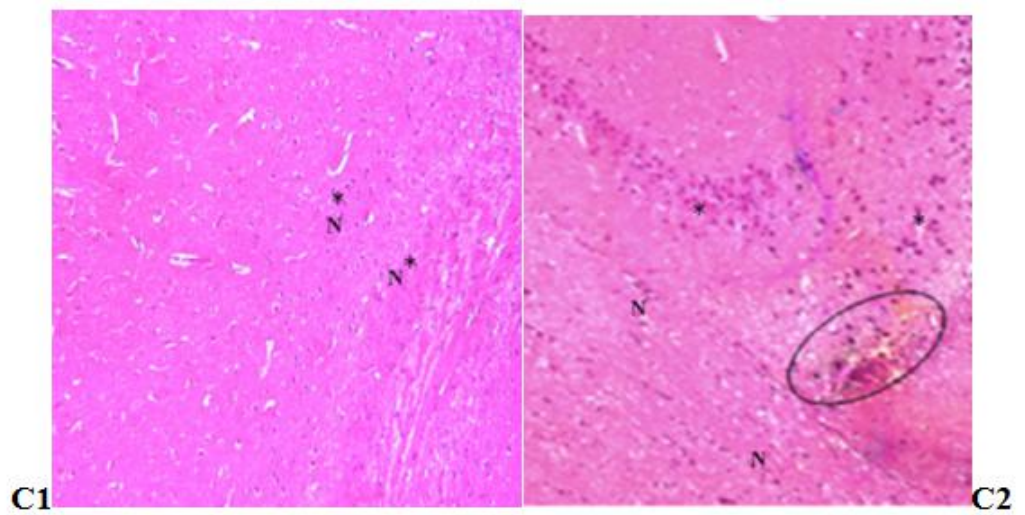

Figure 7: Histological analyses in the brain tissues in rats treated with $\mathrm{ZnO}-\mathrm{NPs}(100 \mathrm{mg} / \mathrm{kg})$ for 5 consecutive days

$\mathrm{C} 1$ control group, the histological analyses in the brain tissues did not show significant changes in morphology and nuclei of neurons were observed (N).C2 treated group showing congestion of vascular (asterisk) and edema (round). C1, C2 magnification $\mathrm{x} 400$. 


\section{Discussion}

The small sizes of the particles can enter and damage the organism allows to penetrate the physiological barriers traveling with circulatory systems ${ }^{[11]}$. The study found that oral exposure to nano-forms was more toxic than micro-counterparts [12].

In the present study, the effects of ZnONPs on RBCs have been investigated in context with the osmotic fragility, hemolysis and morphological features of RBCs. Fragility of RBCs represents stress on the membrane due to osmotic and mechanical stress; osmotic stress is due to the pressure caused by the flow of hypotonic solution; osmotic fragility is also related to the composition, integrity, size of the cell and/or surface area to volume ratio. The fragility of red blood cells is related to some of the diseased conditions like hereditary spherocytosis, hypernatremia, anemia, thalassemia, and sickle cell anemia. ${ }^{[13,14]}$ Mechanical fragility of RBCs refers to the stress caused due to some kind of shear stress during diagnostic testing of blood, handling devices, manipulation of blood during dialysis or intraoperative auto transfusion, storage of red blood cells (storage lesions) and/or applications during blood transfusion and blood bank. ${ }^{[15,16]}$

In current study, all of the RBCs did not hemolyzed at the same time when treated with ZnONPs, some RBCs took more time, and some became crenated while some remained turgid for relatively longer duration (Fig 4A, 4B) Similarly in this study ZnONPs were found to influence the membrane of red blood cells without breaking it i.e. degree of hemolysis increased slightly with increase in the concentration of $\mathrm{NaCl}$ under isotonic condition.

Percentage hemolysis was found at $0.1 \%, 0.2 \%$, $0.3 \%$ and $0.4 \%$ of $\mathrm{NaCl}$, as reference points. These concentrations of $\mathrm{NaCl}$ were involved while studying the effects of $\mathrm{ZnO}$ NPs on hemolysis of red blood cells.

The reason why erythrocytes do not show immediate damage when exposed to toxic substances is because they have a system of antioxidant defense that includes non-enzymatic antioxidants such as glutathione and antioxidant enzymes such as catalase and peroxiredoxin-2 $2^{[17,18]}$
The presence of this defense system could explain their resistance to the damage induced by nanoparticles, indicating that these cells are not as sensitive to the toxic effects of nanoparticles.

ZnONPs can spread more in blood, kidney, liver and other organs. ${ }^{[19]}$ This study agrees with Sharma V. et al results ${ }^{[20]}$ showed that oral acute exposure to $\mathrm{ZnONPs}$ causes apoptosis in mice liver cells and induces severe oxidative stress. Histopathological section showed that ZnONPs is able to induce changes in tissues of kidney and liver in albino male mice. Liver damage could be induced due to excess oral $\mathrm{ZnONPs}$, and this agrees with another study in 2012. ${ }^{[21]}$

Additionally, the histopathological examination may be helpful in detecting organs abnormalities after ZnONPs uptake by the gastrointestinal tract. The results of this experimental study indicated that ZnONPs in mentioned concentration $(100 \mathrm{mg} / \mathrm{kg})$ don't show significant effect on the body weight gain and the relative organs weight. This is in accordance with our previous finding indicating the absence of toxic signs and mortality in adult rats exposed to $\mathrm{ZnO}$ NPs. ${ }^{[21,22]}$

Sharma et al.(23)showed that nanoparticles were mainly found to be retained in the liver after 14 day of sub-acute oral exposure to ZnONPs at a higher dose $(300 \mathrm{mg} / \mathrm{kg})$. However, Matsumoto et $\mathrm{al}^{[23]}$ suggested that repeated oral gavage of nanoparticles reached the gastro-intestinal tract as agglomerates and were mostly excreted via faeces but no investigations and results to support this suggestion were presented. However histopathological analysis of the kidney showed intratubular protein deposition (IPD) but no significant glomerular changes.

In the current study, oral exposure to ZnONPs did not cause significant changes in the activity of mice. This result is in accordance with our previous study indicating the absence of correlation between zinc accumulation in brain following the oral administration of ZnONPs and the behavioral performances of rodents. ${ }^{[24]}$

Our results revealed many histopathological and ultrastructural changes in the brain and spinal cord such as congestion and mild degeneration to severe degeneration associated with ultrastructural disturbance in the neuronal cells and apoptotic 
degenerative cells. These results are consistent with Migliore and colleagues. ${ }^{[25]}$ who reported that zinc oxide nanoparticles cause neurodegeneration in the brain tissues, and in agreement with Win-Shwe and Fujimaki ${ }^{[26]}$ who showed that the toxic effects of zinc oxide nanoparticles on the central nervous system include cytotoxicity, inflammation, and oxidative stress induction that result in neurodegeneration.

According to Nguyen, $\mathrm{H}^{[27]}$ the mechanism of zinc oxide nanoparticle toxicity depends on the oxidative stress generation that causes an inflammation process based on the activation of inflammation related genes. In the same context, it has been shown that the oxidative stress of zinc oxide nanoparticles have the ability to affect the integrity and permeability of blood-brain barrier via inducing endothelial cell leakiness and pro inflammatory mediators, which is in agreement with Setyawati, M.,\& Giovannia, M. ${ }^{[28,29]}$

Neurotoxicity may also occur via a direct effect on the brain itself or by an indirect systemic inflammatory effect. In the contrasting context, Zheng,Y. et $\mathrm{al}^{[30]}$ confirmed that zinc oxide nanoparticles don't have any toxic effect on the brain tissues, which is in agreement withWang,et.al. ${ }^{[31]}$ The results of the present study together with those of previous studies of ZnONPs is not clear, but may involve probably the impairment of the active transport processes or ions exchange mechanisms in the brain.

\section{Conclusion}

The results of the present study together with those of previous investigations showed that effects of oral nanoparticles exposure are less remarkable than those observed for parenteral administration. The oral route is probably one of realistic way of modeling nanoparticles exposure in humans. In the present investigation oral exposure to moderate dose of $\mathrm{ZnO}$-NPs has no significant main effect on the behavior of the rodents and causes subtle signs of toxicity.

Further characterization of nanoparticles in the gastrointestinal tract, including both absorption and excretion in response to $\mathrm{ZnONPs}$ intake are needed.

\section{References}

1 Bakhshiani S., Fazilati.S.Vitamin C can reduce toxic effects of Nano Zinc Oxide. Intern.Res.J.Biol.Sci. 2014; Vol. 3(3):65-70. DOI: 10.21608 /ejfsat.2016.41638

2 Berry C.C., Wells S.,Dalby M.J. Nanomaterials for Environmental Applications and their Fascinating Attributes. Int.J.Pharm.,2004, 269(3):211-225.

DOI:org/10.1016/j.ijpharm.2003.09.042

3 Altaf H, Revell PA. Evidence for active antigen presentation by monocyte/macrophages in response to stimulation with particles: the expression of NFkappaB transcription factors and costimulatory molecules.

Inflammopharmacology 2013; 21(4): 279-290 DOI: $10.1007 / \mathrm{s} 10787-013-0170-\mathrm{Z}$

4 Fan Z, Lu JG. Zinc oxide nanostructures: synthesis and properties. J Nanosci Nanotechnol 2005; 5(10): 1561-1573 [PMID: 16245516 DOI: 10.1166/jnn.2005.182]

5 Kumari L. Li W.Z.Synthesis, structure and optical properties of zinc oxide hexagonal microprisms. Cryst. Res. Technol.2010,45:311-315. DOI 10.1002/crat.200900600

6 Saman S., Moradhaseli S. Shokouhian A., Ghorbani M. Histopathological Effects of $\mathrm{ZnO}$ Nanoparticles on Liver and Heart Tissues in Wistar Rats. Int. j.Nano Sci. 2013, 12(4): 8388. DOI : 10.7243/2055-091X-5-4

7 Abbasalipourkabir R, Moradi H, Zarei S, Asadi S, Salehzadeh A, Ghafourikhosroshahi A, Mortazavi M, Ziamajidi N. Toxicity of zinc oxide nanoparticles on adult male Wistar rats.

Food Chem Toxicol 2015; 84: 154-160 [PMID: 26316185 DOI: 10.1016/i.fct.2015.08.019]

8 Surye P. Synthesis and characterization of zinc oxide nanoparticles by sol-gel process.National Institute of Technology Rourkela,Orissa,India, 2012,12(2):136.DOI:10.5923/j.nn.20150501.01

9 Bancroft J.and Gamble M., Theory and Practice Histological Techniques, 5th Ed., Churchill Livingstone. New York, USA, 2002, 173-175.

10 Hobbie R.k., Roth. B.G.Osmotic fragility. In: intermediate physics for medicine and biology. 
4th ed. New York, NY. Springer.2006; DOI: 10.1119/1.3223440

11 Wang J, Zhou G, Chen C, Yu H, Wang T, Ma Y, Jia G, Gao Y, Li B, Sun J, Li Y, Jiao F, Zhao Y, Chai Z. Acute toxicity and biodistribution of different sized titanium dioxide particles in mice after oral administration. Toxicol Lett 2007; 168(2): 176-185 DOI: $10.1016 /$ j.toxlet.2006.12.001

12 Dhawan A., and Sharma V., Toxicity assessment of nanomaterials: methods and challenges. Anal Bioanal. Chem. 2010,398: 589-605. DOI: 10.1007/s00216-010-3996

13 Rodak F., Bernadette S. Hematology, clinical principles and applications, Elsevier Health Services, 2007,p-291. DOI: 10.1016/02484900(93)90117

14 Frances F., Talaska A., Marshall D., A manual of laboratory and diagnostic Tests,8th Ed.2008

15 Yazer M.H., Waters J.H., Elkin K. A., et.al., A comparison of hemolysis and RBCs mechanical fragility in blood collected with different cell salvage suction devices', Transfusion. 2008, 48: 1188-119.DOI: 10.1111/j.1537-2995.2008.01670.x

16 Vox Sang W., The use of mechanical fragility test in evaluating sub-lethal RBCs injury during storage, Vox Sang, 2010, 99(4):325331. DOI: $10.1111 / \mathrm{j} .1423-0410.2010 .01365 . \mathrm{x}$

17 Lee TH, Kim SU, Yu SL, Kim SH, Park DS, Moon HB, Dho SH, Kwon KS, Kwon HJ, Han YH, Jeong S, Kang SW, Shin HS, Lee KK, Rhee SG, Yu DY. Peroxiredoxin II is essential for sustaining life span of erythrocytes in mice. Blood 2003; 101(12): 5033-5038 [PMID: 12586629 DOI: $10.1182 /$ blood-2002-08-2548]

18 Gonzalez R., Auclair C., Voisin C., Gautero H.,et.al. Superoxide dismutase, catalase, and glutathione peroxidase in red blood cells from patients with malignant disease. Cancer Research.1994, 44:137-4139. PMID: 6589047

19 Hillyer JF, Albrecht RM. Gastrointestinal persorption and tissue distribution of differently sized colloidal gold nanoparticles. $\boldsymbol{J}$ Pharm Sci 2001; 90(12): 1927-1936 [PMID: 11745751 DOI: $10.1002 / j p s .1143]$

20 Sharma V, Singh P, Pandey AK, Dhawan A. Induction of oxidative stress, DNA damage and apoptosis in mouse liver after sub-acute oral exposure to zinc oxide nanoparticles. Mutat Res 2012; 745(1-2): 84-91 DOI: 10.1016/j.mrgentox.2011.12.009

21 Sanaa A.A.,Maha Z.R., Samy A.A.,Hebatallah A.D. Roll of potent antioxidants in regulation of SMAD-2 transcription and TGF-B1 signaling in nano sized titanium dioxideinduced oxidative injury in mice liver. Inter. $\boldsymbol{J}$.

Pharma. 2015,5:17-26.

DOI: $10.1155 / 2015 / 654594$

22 Amara S, Slama IB, Omri K, El Ghoul J, El Mir L, Rhouma KB, Abdelmelek H, Sakly M. Effects of nanoparticle zinc oxide on emotional behavior and trace elements homeostasis in rat brain. Toxicol Ind Health 2015; 31(12): 12021209 DOI: $10.1177 / 0748233713491802$

23 Matsumoto M, Serizawa H, Sunaga M, Kato H, Takahashi M, Hirata-Koizumi M, Ono A, Kamata E, Hirose A. No toxicological effects on acute and repeated oral gavage doses of single-wall or multi-wall carbon nanotube in rats. J Toxicol Sci 2012; 37(3): 463-474 [PMID: 22687986 DOI: $\underline{10.2131 / \text { jts.37.463] }}$

24 Amara S, Ben-Slama I, Mrad I, Rihane N, Jeljeli M, El-Mir L, Ben-Rhouma K, Rachidi W, Seve M, Abdelmelek H, Sakly M. Acute exposure to zinc oxide nanoparticles does not affect the cognitive capacity and neurotransmitters levels in adult rats. Nanotoxicology 2014; 8 Suppl 1: 208-215 DOI: $10.3109 / 17435390.2013 .879342$

25 Migliore L, Uboldi C, Di Bucchianico S, Coppede F. Nanomaterials and neurodegeneration. Environ Mol Mutagen 2015; 56(2): 149-170 [PMID: 25627719 DOI: 10.1002/em.21931]

26 Win-Shwe T. Fujimaki T., Nanoparticles and neurotoxicity. Int.J.Mol. Sci.2011, 12: 626780. DOI:10.3390/ijms12096267

27 Nguyen H.,Barr T. O.,Anderson A., Sub-Acute Oral Toxicity of Zinc Oxide Nanoparticles in Male Rats.J. Neurochem., 2007, 102: 900-12.

28 Setyawati M., Tay C., Leong D., .Effect of zinc oxide nanomaterials-induced oxidative stress on the p53 pathway.Biomaterials 2013,34: 10133-10142 . DOI: $10.1016 / 2013.09 .024$

29 Giovannia M., Yue M., Zhang L., Xie J., The Impact of Engineered Silver Nanomaterials on 
the Immune System.J. Hazard Mater.2015, 297: 146-152

30 Zheng Y., Li R., Yang Y., B. The toxic effects and mechanisms of $\mathrm{CuO}$ and $\mathrm{ZnO}$ nanoparticle.Int. J. Mod. Phys.2009,23: 15661571.
31 Wang B,Feng W.,Wang M.,Wang T.,et.al.Zinc oxide induce oxidative DNA damage and ROS-triggered mitochondria mediated apoptosis in human liver cells.J.Nanopart. Res. 2008,10: 263-276. 